The following paper is intended to spur further discussion in the forthcoming issue of Gestalt Theory

Anton Yasnitsky

\title{
Cultural-Historical Gestalt Theory and Beyond: A New History (and Theory) of the "Informal Personal Network" of Intellectuals Is Needed
}

\section{A Fresh Outlook on Gestalt Theory (Is Needed)}

There are a great many good books and scholarly papers of Gestalt psychology and about it. And yet, a fresh account of Gestalt theory/psychology as an informal personal network is needed. One might disagree, given the diversity and the amount of published research on this topic available these days. Still, I would argue that this very argument can also be used to the contrary effect: we still do not have a single study performed from a consistent methodological standpoint that would capitalize on the diversity of the available exciting - yet fragmented and isolated-studies that would eventually close the gap between the historiographies of different kinds, such as "social", "personal", and "intellectual" histories of the major (and, importantly, not so major) personalities serving as protagonists of the history of science. Such major revision of the historiography will inevitably lead us to a better understanding of their ideas and theories as a coherent whole (regardless of what this new synthesis will be called as a result, a "cultural-historical Gestalt theory" or anything else), as productive and promising as they are in the context of our times, the 21 st century. The unifying new frame of reference and the conceptually novel research toolkit for this revisionist approach to Gestalt psychology/theory is provided by the methodology of research into "informal personal networks" and "circles" of intellectuals and their associates, as I proposed earlier (Yasnitsky, 2021c). ${ }^{1}$ This paper and its sequel that comes out in this very special issue of this journal (Yasnitsky, 2021b) are supposed to provide an extension of this earlier proposal, and they present a discussion of its consequences for the historiography and theory of Gestalt theory.

From the standpoint of a unified social and psychological research on the group of individuals, this new historiography would need to take account of the entire unitary network of intellectuals with a specific focus on their social and intellectual

\footnotetext{
This important (at least, for its author) — and somewhat lengthy_-text was first orally presented in the spring of 2021 as a Guest Lecture at the United Arab University in Al Ain and is, in fact, a manuscript of a book in progress; available online at http://individual.utoronto.ca/yasnitsky/texts/Yasnitsky_2021_revNoRev.pdf
}

O Open Access. ( 2021 Anton Yasnitsky, published by Sciendo. (c) BY-NC-ND This work is licensed under the Creative Commons Attribution NonCommercial-NoDerivatives 4.0 License. 
roles, such as those of a "spokesperson", "broker", "patron", "team player", "theorist", "critic", "entrepreneur", etc. The work of this type is very complex, onerous, and time-consuming and requires considerable effort. Yet, precedents are known of research of the kind that was done on the material of the "Vygotsky(-Luria) Circle" more than a decade ago (Yasnitsky, 2009, 2011), and it seems highly promising and potentially very rewarding as long as the transition from a pure historiography to an intellectual history is concerned.

As a point of departure and in order to launch a meaningful discussion, we need to establish what "Gestalt psychology" is, where it came from, who represented the larger "Gestaltist network", and what exactly their ideas were in strict relation to each other. Let us start with the minimalist and simplistic "textbook version" of Gestalt psychology that can be found, for instance, in the encyclopedic entry in the English Wikipedia. This version can be summarized, perhaps, in three statements: Gestalt psychology is (a) a tradition of psychological research originated by the threesome (the "troika", in Russian, as known by the references to the somewhat mythical trio of Vygotsky—Luria—Leontiev) of the Founding Fathers in Germany, namely, Max Wertheimer, Wolfgang Köhler, and Kurt Koffka, (b) whose main achievement and claim for fame was in the field of the psychology of perception, and (c) its main postulate is that "the whole is more than the sum of its parts". To these, one can add a popular opinion that, founded in early 20th century, Gestalt psychology reached its blooming and international acclaim in the interbellum period of 1920s-1930s, in order to gradually step down after its topmost proponents left Germany (mostly for the United States) in the aftermath of the Nazi takeover of power in this country in 1933 and ultimately reach the status of a somewhat outdated "historical theory" in psychology with its well-deserved place in the majority of the textbooks on the history of psychology (read: the history of American psychology, a frequent, but quite essential omission in most of writings on psychology as a discipline, at least those composed in this language), but virtually nothing more than that. This paper strongly contests most—if not all—of these claims.

\section{The "Berlin School" Versus the "Berlin Circle"}

Let us start with the obvious. The obvious is that the notion of the "Berlin School" is fairly problematic, to say the least. Indeed, the majority of the key figures in the "Berlin School" narrative finished their graduate studies in Berlin University with their doctoral dissertations accomplished under the supervision of the founding Director (in 1894-1922) of the Berlin Psychological Institute, Carl Stumpf: these are Kurt Koffka (Experimentelle Untersuchungen zur Lehre vom Rhythmus, in 1908), Wolfgang Köhler (Akustische Untersuchungen I, in 1909), and Kurt Lewin (Die psychische Tätigkeit bei der Hemmung von Willensvorgängen und das Grundgesetz der Assoziation, in 1916). To these should be 
added the name of Adhémar Gelb, another student of Stumpf, as the only one whose dissertation project explicitly discussed the notion of "Gestalt" as reflected in the very title of his dissertation (Theoretisches über Gestaltqualitäten, defended in 1910) (Ash, 1995, pp. 419-420). The legendary founder of "Gestalt psychology", Max Wertheimer, took a course of studies in Prague (from 1898), then in Berlin (from 1900, under Carl Stumpf and Friedrich Schumann), and then in Würzburg (under Oswald Külpe and Karl Marbe), where he finally defended his doctoral dissertation Experimentelle Untersuchungen zur Tatbestanddiagnostik (on November 30,1904) (Stock, 2015), his doctoral work in Würzburg being a "direct outgrowth of the work that he had begun several years earlier with [Julius] Klein at the University of Prague" (King \& Wertheimer, 2005, p. 57). True, all these scholarly contributions were related to Berlin, yet they hardly constituted any "Berlin School" whatsoever-at least not in the sense it is presented in the traditional narrative.

The next major point in the traditional history of the "Berlin School" is 1910, when the legendary meeting of the three Founding Fathers took place and, presumably, the "Gestalt psychology" of Wertheimer, Köhler, and Koffka was born. Yet, the meeting took place in Frankfurt, not Berlin. Furthermore, Kurt Koffka branched off of the main group as a professor (from 1911) (Harrower, 1983, p. 259) and the founding Director (from 1919) of the Psychological Institute in the University of Giessen (Ash, 1995, p. 414). Furthermore, he eventually moved to the United States in 1927, and — even before that - he had a series of temporary appointments in this country from 1924 (Harrower, 1983, pp. 259-260), which extends the expatriate period of his career to an impressive 17 years (out of the total of 55 years of his entire life). Thus, from a purely geographical standpoint, he can hardly be regarded as a true member of the "Berlin School" (or the "Berlin Circle" proper), which already poses a serious problem to any notion of the "Berlin School" of Wertheimer-Köhler-Koffka as such. An aside note is in place: it appears that the construct of the "Berlin School" is a product of North American thought and perception as it was developed by the "Berliners" former local students, primarily after WWII, in order to retrospectively delimit the group of German émigré scholars in the United States as the "most important representatives" and the "major leaders" of the Gestalt tradition. Thus, the logic of the construct starts getting somewhat circular at this point by virtue of equating the "Berlin school" founders with American emigrants and vice versa. This approach, however, hardly does justice to those important representatives of Gestalt psychology who did not leave Germany in the Nazi Party era and remained the major proponents of this intellectual tradition in Europe after the war, such as Wolfgang Metzger, Kurt Gottschaldt, and 
Edwin Rausch, the leaders of the so-called "second generation" of the Gestalt theory in Germany.

Unlike the "Berlin School", the notion of the "Berlin Circle" as a robust intellectual hub within a network of informal personal contacts between like-minded individuals appears way less mysterious and easier to observe and research. It seems, we are all familiar with the situation of a group research meeting and are fully aware of its importance. Yet, the main rationale for our preference of the notion of interpersonal "circle" as a place and situation of regular direct meeting point for intellectuals to discuss their work and ideas is the fact that it is exactly this situation that is the key event in the work of a research collective when most of the innovative and creative "Aha-experiences" (Aha-Erlebnisse)—also known as the "eureka effect" - take place. An excellent description of this situation can be found in a research paper that presents a ground-breaking cognitivist field study on "how scientists think" in "live" real-world contexts, specifically, on the "online creativity and conceptual change in science":

My goal was to identify the points at which creative scientific thinking occurred. What I discovered was that one of the central places in which new ideas and concepts were generated was the laboratory meeting. Each laboratory has a weekly meeting that all the members of the lab attend. The senior scientist who runs the lab is present as well as the post-doctoral fellows, graduate students and technicians. Lab meetings consist of a scientist, presenting his or her latest research that is conducted with the senior scientist who is running the laboratory. Members of the lab ask questions about the research, propose new experiments, hypotheses and interpretations, often forcing the presenting scientist to reconceptualize his or her ideas. At some meetings totally new concepts are generated and modified by members of the laboratory. Often the senior scientist who runs the laboratory plays a crucial role in the development of new ideas and concepts at the meeting. The scientists' reasoning at lab meetings is often spontaneous and the online interactions concern some of the most creative moments in science. The finding that lab meetings are a central source of creative thinking and reasoning is also important because the reasoning that occurs at these meetings occurs through presentations and spontaneous interactions in which the scientists develop their ideas. Because the scientists are talking out loud there is an external record of thinking and reasoning (Dunbar, 1997).

This is a splendid and amazingly precise description of how an ordinary and regular research meeting in Berlin Circle in all likelihood would take place. A very interesting specific example of how such a research meeting actually looked like can be found in a published protocol of the research meeting in the Berlin Institute of Psychology on December 7, 1925. The central topic of this meeting was Kurt Lewin's student Tamara Dembo's presentation of her research in progress and the 
group research meeting included an amazing number of different participants; not all of these would appear familiar even to the most erudite experts on the history of Gestalt psychology/theory. Thus, the names of only those participants who openly entered into discussion (in the order of their joining the conversation and exactly as indicated in the protocol) are Dembo, Wertheimer, [von] Allesch, Gottschaldt, Frl. Janz, Lindemann, Voigt, Os, Lewin, Freund, Dr. Jablonski, Fr. Dr. Frank, and Fränkel. The anonymous participant of the research-indicated in the protocol as a "VP" (an abbreviation from Versuchsperson, in German).

Apparently, other than Wertheimer, neither of the remaining members of the legendary Founding Fathers "troika" ("the threesome", in Russian) - the Psychological Institute's director Köhler and Koffka_participated: at that time, both were overseas, visiting (and temporarily residing in) the United States. This fact does not strike us as surprising at all: Köhler was an officially appointed Director of the Institute of Psychology in Berlin after Karl Stumpf in 1922, therefore, presumably committed to a great deal of administrative duties of various sorts that might have distracted him from direct research matters. Besides, on a number of occasions, he would be on leave, going from Berlin to the United States in 1925/6, then, to Spain in 1930 and South America in 1932. In contrast, Lewin and Wertheimer were the two who would be always there, in Berlin, in direct contact with the researchers on the ground, at least until Wertheimer's departure to the University of Frankfurt in 1929. Thus, for instance, both Lewin and Wertheimer were in town in mid-1925 when their younger Soviet peers, Lev Vygotsky and Alexander Luria independently and for different reasons visited Berlin and first met German psychologists there; therefore, Vygotsky's quoted somewhat enigmatic reference to a "conversation with one of the most educated psychologists" in all likelihood implied either of the two, although it is still not quite clear who exactly this might have been. Again, this is yet another argument in support of our focus on "circles" as a concretely historical and-especially_psychological unit of analysis of joint group activity in science versus a somewhat dry and overly abstract notion of "scientific school" as an embodiment of an "ivory tower" intellectual construct.

Interestingly, the participants of the meeting included quite likely not only members of the German-speaking psychological community, at least not as it is circumscribed in the specialized Personenlexicon (Wolfradt, Billmann-Mahecha, \& Stock, 2015). This is a characteristic of informal personal "circles" as such: their membership is relatively open, flexible, and dynamic; despite the core membership as its nucleus being more or less settled, certain face-to face meetings might include interested (and, possibly, expert) guests, who might well also meaningfully and importantly contribute to discussion, therefore, providing new and unexpected input from an unusual perspective, for instance, ideas from a different field of knowledge or scholarly discipline. Thus, for instance, an observer of the everyday 
activities in the Psychological Institute under the auspices of Berlin University left us an interesting comment on the meeting of the Philosophical Society that took place in the spring of 1923 in Erlangen, a German town near Nürnberg, "where the Philosophical Society had a house that served just such occasions":

The house turned out to be an enormous mansion, all the rooms of which were named after famous philosophers. Lewin and I were assigned to the Aristotle Room. Besides us were seven or eight other people, among them Rudolf Carnap and Hans Reichenbach (Heider, 1983, pp. 49-50).

The proximity of the "psychologists" and the "philosophers"— such as Carnap and Reichenbach - from Berlin University on their trip to Erlangen in 1923 was neither incidental nor merely "topological" - the reference to "topology" is fairly ironic, as the reader will see demonstrated in the section of this paper that deals with the "frontiers of experimental psychology". In the meantime, in anticipation of the subsequent discussion, consider a statement: "Kurt Lewin and Hans Reichenbach have been central figures in the birth of logical empiricism as well as in the Berlin Group" (Padovani, 2013, p. 97), where the reference to the "Berlin Group" is meant to designate the individuals who worked in the Berlin tradition of philosophical investigation, globally known as "logical empiricism" (alternatively, albeit not quite identical, "logical positivism" most often associated with the "Vienna Circle", yet frequently used interchangeably). This suggests that the "Berlin Circle" we are dealing with in this paper should be regarded in much broader terms and, thus, needs to include not only self-identified psychologists but also representatives of other fields of knowledge: among these, the "Berlin group" of philosophers (of science) stands out as the first and the most obvious candidate for inclusion.

Overall, publication of documents such as the "Vortrag von Fräulein Dembo über ibre Versuche, mit anschließenden Fragen" (Dembo, 2002)—especially, like in this very instance, properly commented by expert researchers (Van der Veer \& Lück, 2002) — clearly demonstrates the yet-unexplored potential of concrete "circle research" and the benefits of this analytic framework over the traditional "school studies" approach.

The task of the reconstruction of the entire "Berlin Circle" as a robust intellectual hub of the "Gestalt network" is relatively simple and nonproblematic. Yet, it challenges us with acute problems of a very novel and different kind. Dealing with a "circle", we necessarily focus on issues of not only sociological or institutional nature but on essentially psychological matters, such as love, affection, sympathy, loyalty, friendship, altruism, generosity, unselfishness, cooperation, sharing, etc., as well as ambitions, egos, power, envy, jealousy, competition, fear, intrigue, betrayal, dominance, arrogance, etc. In order to understand these internal intricacies, 
we need reliable data, such as a gallery of remarkable psychological portraits of the three protagonists of the Berlin Circle-Wertheimer, Köhler, and Lewinwhich can be found in the memoirs of a contemporary, a peripheral member of the Circle, quite sympathetic to the Gestalt movement and its members in general, furthermore, a husband of one of them, yet an outsider to the movement as such and an international mediator, a "broker", between different geographical variations of "Gestaltism" outside Berlin (Heider, 1983, pp. 42-46). Furthermore, the memoirist remarked:

I naturally found myself comparing the Berlin group—and here I mean principally Wertheimer and Köhler-with Graz's Meinong, Spitzer, and Benussi. There was, of course, a connection between the Graz school and Berlin. For one thing, Christian von Ehrenfels, whom the Berlin group recognized as one of their precursors, had been one of Meinong's students, and Wertheimer was said to have attended lectures, in his student days, by Ehrenfels at the University of Prague. Both groups were concerned with superelementary structures, the so-called Gestalten. Benussi and the Berliners had high regard for each other in spite of the fact that they differed in their theories about these organized units and also in their emotional attitudes towards their theories. The Berliners seemed always to be engaged in a sort of holy war against nonbelievers; they were much more belligerent and militant than the Graz group. They were fervid partisans of all the ideas that have to do with configurations and with every kind of superunit or totality. For them, the very thought of attempting to derive these noble "whole qualities" from despicable elements or pieces was unspeakably sinful, a clear sign of deplorable and corrupt thinking. They also hated the idea that mere chance could ever lead to any kind of order. Certainly, gestalt theory, as I knew it, at this time in Europe, was mainly shaped by its opposition to elementarism; but later, in America, its opposition to behaviorism was much more important (Heider, 1983, pp. 44-45).

In addition, the memoirist discusses a special event. This was a scholarly meeting and discussion that took place in Germany in the spring of 1928 and whose participants included Lewin, Wertheimer, and Köhler (from Berlin), Michotte (from Louvain, Belgium), Rubin (from Copenhagen, Denmark), Werner and Heider (from Hamburg), and, finally, David and Rose Katz, "acting as our hosts in Rostock": "they were all either gestalt psychologists or were closely associated and in sympathy with the ideas of the gestalt group" (Heider, 1983, p. 89). For a very curious and, in a certain sense, very characteristic image of the participants of the meeting, see the photograph from the personal archives of the memoirist (Heider, 1983, p. 90).

This firsthand evidence is very curious and suggests two remarks. First: from the first quote description, one cannot avoid the feeling of a fairly aggressive, militant style of the "pure Gestaltist" Berliners, their intolerance and somewhat 
"prophetic", "missionary" (and messianic) and "proselytizing" attitude. Were it true, this might have well served its service to the group in their striving to establish themselves among other similar research groups in Weimar Germany and beyond its borders, but it is hardly the attitude and style that will help us build an integrative science about human beings nowadays, in the 21 st century.

Second, the memoirs highlight the multitude of "Gestaltist" groups then and suggest to question the place of the "Berlin School" among other-in some instances, rival and competitive- "Gestalt Schools" like the mentioned groups of scholars in Austria and Italy or, not yet mentioned, the entire tradition of Ganzheitpsychologie of Wilhelm Wundt's students and psychologists in Leipzig, who worked not only in the footsteps of Wundt's "experimental psychology" but also in the spirit of his Völkerpsychologie research program (subsequently, with all its quite unfortunate Nazi ideology connotations as rendered with the political call for the national unity and totality as expressed in an infamous slogan "Ein Volk, ein Reich, ein Führer").

Furthermore, the reader should be aware of an illuminating comment left by an attendee of the XII Congress of the German Psychological Society (XII. Kongress der Deutschen Gesellschaft für Psychologie), which took place in Hamburg between April 12 and16, 1931 (under the leadership of its chair, Karl Bühler)—an outsider observer from Soviet Russia-who reported his impression that, as of 1931, the Congress was a "demonstration of a full victory of holistic-dynamic perspectives over the elementarist and mechanicist points of view" and argued that the entire psychological community in Germany of the period shared the unified integrative approach to human being in general-theoretical and specific experimental works, in principle (Artemov, 1932, p. 96).

\section{The Core and the Periphery of the Gestalt Network}

From the perspective and research lens of "personal informal networks", the Gestalt theory presents a rather puzzling image. Indeed, the problem and the question are formulated from an entirely Gestaltist standpoint: what figures constitute the personal network of Gestaltists in its entirety? The traditional, canonic narrative associates it primarily with the three Founding Fathers, namely, Max Wertheimer, Kurt Koffka, and Wolfgang Köhler. The figure of Max Wertheimer is posed as the discoverer of the "phi phenomenon" (and this event is presented as the actual founding of the theory as such), the leading founder of the Gestaltist movement as its prime ideologue and "Gestalt prophet" (Wertheimer, 1980), if not the public spokesman: for that role, the figures of Kurt Koffka and Wolfgang Köhler look like more appropriate candidates, in the Anglo-Saxon context at least; consider the pioneering publications of the two in English, which introduced the "Gestalt theorie" and "Gestalt psychology" to the Anglo-Saxon readership in the 
1920s (Koffka, 1922; Köhler, 1929). The three individuals, thus, solidly represent the core of the entire network, it seems. This account immediately provokes numerous acute questions. For instance, one might question the place of Kurt Lewin in this construct. A member of the Berlin Circle from 1921 and its most active participant and contributor to the cumulative intellectual heritage of the Gestalt tradition, Lewin is mentioned as one of the leading figures of this intellectual movement indeed; yet, according to some other accounts, he is only a peripheral member of this Circle outside of its core; one such interpretation can be found, for instance, in the paper by Harrington (1996) and not only there. Furthermore, there are even alternative presentations of the network, which totally exclude Lewin's work from the essential "documents of Gestalt psychology" (Henle, 1961). Another example of the kind is the figures of Kurt Goldstein and Hans Walther Gruhle, both founding members and coeditors of the specialized and programmatic scholarly journal of Gestaltists Psychologische Forschung - Zeitschrift für Psychologie und ihre Grenzwissenschaften, along with Wertheimer, Köhler, and Koffka. Both can be understood, perhaps, not as psychologists proper, but as the representatives of the Grenzwissenschaften, i.e., the "bordering sciences" such as the biomedical spectrum of disciplines and practices; yet, their place in the entire network and contribution to the theory as such can —and often is—contested as somewhat problematic; see, e.g., Ash (1995).

The problems even further worsen from the standpoint of the search for the entire network that stems from its core. Thus, for instance, it took about half a decade of 1933-38 for a great and the most enthusiastic supporter of the Gestalt theory from the United States, Willis D. Ellis of the University of Arizona (as of 1938), to have prepared-under the guidance of and in closest direct contact with Koffka—a programmatic "source book" with abbreviated translations into English, the volume subtitled as "summaries of thirty-four articles and one book published in Germany by the leading exponents between 1915 and 1929 of Gestalt Psychology" (Ellis, 1938). The (last) names of the "leading exponents" in the order of their appearance in the book included the following: Wertheimer, Köhler, Fuchs, Benary, Gottschaldt, Wulf, Ternus, Duncker, Lindemann, Hartmann, v. Frey, Gelb, v. Hornbostel, Hertz, Lewin, Zeigarnik, Goldstein, Schulte, and Koffka. Apparently, the presence of a few names (seemingly, absolutely obscure to the contemporary reader without an in-depth knowledge of the history of this intellectual movement and, especially, proficiency in German language reading), as well as the absence of a few others, might seem really puzzling. It seems instructive, thought-provoking, and even further puzzling to compare this list with another list of (only last) names of the authors of "Berlin dissertations supervised by Wolfgang Köhler, Max Wertheimer, and Kurt Lewin" (in 1922-1937), as well as those of "Giessen dissertations supervised by Kurt 
Koffka" (1915-1928), in chronological order according to dissertation defense year (Ash, 1995, pp. 421-423): Eberhardt, Scholz, Schur, Ternus, Meili, Metzger, Gottschaldt, Zeigarnik, Liebmann, Karsten, Ovsiankina, Arnheim, Duncker, Hoppe, Dembo, Voigt, Lauenstein, Wolff, Berger, Forer, Fajans (Glück), Mahler, v. Restorff, Jakobs, Lissner, Sliosberg, Calavarezzo, Wolff, Wallach, Simon, Jucknat, Bartel, Ortner, and Müller (all in Berlin); Korte, Kenkel, Wulf, Lindemann, Hartmann, Ackermann, Feinberg, Hartgenbusch, Noll, Kester, Stern, and Mintz (all in Giessen). Even a cursory overview of these two lists unavoidably creates a sense of how little we still know about the entire "Gestalt of the Gestaltist network" as a unified whole, a social-intellectual superindividual unity of researchers-in prewar Germany only. Yet further complications with the holistic prospect on this network arise if we consider the names of all those authors who ever published their studies in the Psychologische Forschung journal (Guss, 2019), which was at least on one occasion informally referred to as "der Zeitschrift der Gestaltpsychologie" (Gundlach, 2015, p. 151), i.e., "the journal of Gestalt psychology", which—even despite the editors' initial explicit claim to the contrary-it was increasingly turning into in its historical development until mid-1930s the latest.

All in all, it is absolutely safe to conclude that we are still very far from the understanding of the Gestalt movement as an "informal personal network" in its numerous and potentially very interesting interconnections with like-minded intellectual movements of its "Golden Age" period. In sum, here is the key statement: our in-depth understanding of the "Berlin Circle" as the intellectual hub of the whole of "Gestalt network" in its most intimate dynamic interrelations and operations (internal and external, alike) is absolutely the key to understanding the entire "Gestalt theory" —as it emerged a century ago, as it developed throughout the whole later period, and, most importantly, how it can strive and succeed as an overarching "human science" intellectual project in the 21 st century.

\section{Terminological and Conceptual Framework: Social Construction of the Theory}

A contemporary researcher of the "receptions, readings and interpretations of Gestaltpsychologie" made an exciting and eye-opening discovery:

Following the images of Gestaltpsychologie of Wertheimer, Köhler and Koffka in 20th century philosophical, epistemological, psychological and science historical literature may be puzzling. Gestaltpsychologie interpretations are various and at times diametrically opposed. Moreover, we may come across strained interpretations, accentuated to various degrees, with generic or metaphoric references. In some cases these are even historically incorrect (Toccafondi, 2002, p. 199). 
This finding strongly corroborates my colleagues' and my own discoveries in the destiny of the notion of "field theory" (Yasnitsky, 2014) or a wide range of "receptions, readings and interpretations" of the Vygotsky-Lurian legacy (Yasnitsky, 2018, 2019; Yasnitsky \& Van der Veer, 2016) or, even broader, the entire "Soviet Marxist psychology" (Yasnitsky, 2021a). Upon consideration, these can be attributed to three possible reasons that might explain the mechanisms of distortions:

First, I would like to start a discussion of this point with yet another illustrative quote, yet again from the highly valuable memoirs of Fritz Heider, on his observations of the interactions and interrelations between the members of the "Founding Troika" of the Gestalttheorie: the context of discussion is the American period with all key figures on American soil by then; the intellectual portraits are succinct and psychologically acute:

During the next years, when Köhler and Wertheimer came to visit the Koffkas, we were often invited to join their gatherings. We watched with great interest and pleasure the interaction between Koffka and the guest of the occasion. In spite of the agreement on principles that made the collaboration of this brilliant trio so fruitful, there were also differences, which meant that each had made his own contribution to their joint product. Wertheimer was the temperamental and inspired artist, Köhler was a somewhat reserved physicist, thinking very much in special terms; and Koffka was the highly verbal lawyer and logician, who tried to bring everything into a total system. We had the impression that Köbler's and Wertheimer's admiration for Koffka was not so great as his for them (emphasis added; Heider, 1983, pp. 119-120).

The quote is curious and telling in a number of ways. Yet, I would like to highlight the crucial—albeit trivial—point: people are different and the interrelations between them are rarely absolutely symmetrical. Each pursues their own agenda, according to their own interests, needs, drives, and preferences. Thus, this is the natural course of events and the first cause of the multiplicity of diverse interpretations of seemingly unified and unanimously held views - in our case, a single theory of like-minded protagonists: the like-minded, yet not identically minded ones.

Secondly, protagonists' differences considered, these are even further aggravated by the differences of opinions among their students and followers, driven, in turn, by agendas of their own, yet multiplied by their affections to their teachers and jealousies related to their "intellectual cousins": the students of other protagonists. The two already mentioned collections of the essential Gestaltists' works and the documents of Gestalt psychology provide a good example of partisanship and a selective presentation of the kind (Ellis, 1938; Henle, 1961). Another example of the kind is a selective and "transformative representation" that Kurt 
Lewin's originally titled "topological (and vector) psychology" (Leeper, 1943; Lewin, 1936) underwent in the process of its posthumous presentation in a volume of collected works on "field theory", prepared by Lewin's American former student and associate Dorwin Cartwright (Lewin, 1951).

Thirdly, another powerful source and the reason for distortions of intellectual legacy is related to the social and cultural traditions (including those in specific local academic culture), especially in the case of knowledge transfer from one social context to another and the perceived need in adaption of the foreign to the local. Yet, adaptation does not necessarily take place in the scenario of knowledge transit: it also occurs in the everyday world, when scientific knowledge in its social presentation and positioning gets adapted to diverse economic, religious, cultural, and political agendas, in its probably most dramatic forms of political correctness of various sorts. Historically, the most radical cases of the latter are presented by the scientific communities under strict and rigorous control of the politically minded supervision of the party-state authorities such as the Communist Party of the Soviet Union or the National-Socialist Party of Germany (also known as the Nazi party). In such cases, the distortions of this variety result from the actions of state censorship imposed on scholarship publications, but most often, an outsider censor is even not needed due to the self-censorship that the authors of scientific texts practice consciously, willingly, and voluntarily. Numerous examples of the impact of political correctness of this sort can be found in the history of the scientific communities in the Soviet Union or Continental Europe under the Nazi rule. A specific example of that is, for instance, an entirely Gestaltist book in its sprit that was published in 1941 by Wertheimer's former student and closest associate Wolfgang Metzger, which—all his profoundly Gestaltist worldview nothwithstanding - avoided virtually any references to the German émigré (and mostly Jewish) scholars, including the most prominent figures of the Gestaltist movement such as Wertheimer, Koffka, Köhler, Lewin, Goldstein, and Gelb, not to mention the scholars of relatively smaller scale (Metzger, 1941). Characteristically, this technique was independently developed and normatively practiced by Soviet scholars in the 1930s and onward among an arsenal of a great many other rhetorical, stylistic, discursive, and argumentative devices of the Soviet "scientific doublespeak", which was analyzed and discussed in a few earlier publications (Gerovitch, 2002; Krementsov, 1997; Yasnitsky, 2009). These most unfortunate cases of self-censorship definitely need to be well understood and kept in mind in our dealing with scientific literature created in the times of increasing political control over the freedom of speech (including the freedom of scholarly self-expression) and in the cultures of predominant aggressive and militant political correctness. 
These three mechanisms seem to be the main causes of the varieties of the Gestalt theory as evidenced in countless and diverse "receptions" of the theory; therefore, a deep understanding of the mechanisms and perfect skills of scholarly discourse "deconstruction", coupled with cultural-historical textological and textual "archeology" are needed to get rid of distortions and (re)produce the ideas in their immaculate and purified form as meant by their originators.

Keywords: informal personal network, scientific circle, Berlin School, Berlin Circle, gestalt network.

\section{References}

Artemov, V. A. (1932). O Gamburgskom kongresse (po dannym XII kongressa nemetskikh psihologov. Gamburg, 12-16 aprelia1931 g. [On the Hamburg Congress (based on the materials of the XII Congress of German psychologists, Hamburg, APril 12-16, 1931)]. Psikhologiia, (3), 86-101.

Ash, M. G. (1995). Gestalt psychology in German culture, 1890-1967: Holism and the quest for objectivity. Cambridge, UK: Cambridge University Press.

Dembo, T. (2002). Vortrag von Fräulein Dembo über ihre Versuche, mit anschließenden Fragen. Im Psychologischen Institut der Universität, Montag d. 7. Dez. 25. Psychologie Und Geschichte, 10(1-2), 56-83.

Dunbar, K. (1997). How scientists think: On-line creativity and conceptual change in science. In T. B. Ward, S. M. Smith, \& J. Vaid (Eds.), Creative thought: An investigation of conceptual structures and processes (pp. 461-493). Washington, D.C.: American Psychological Association.

Ellis, W. D. (Ed.). (1938). A source book of Gestalt psychology. London: Routledge \& Kegan Paul.

Gerovitch, S. (2002). From Newspeak to Cyberspeak: A History of Soviet Cybernetics. Cambridge, MA: MIT Press.

Gundlach, H. (2015). Gruhle, Hans Walther. In U. Wolfradt, E. Billmann-Mahecha, \& A. Stock (Eds.), Deutschsprachige Psychologinnen und Psychologen 1933-1945. Ein Personenlexikon, ergänzt um einen Text von Erich Stern (pp. 149-151). Wiesbaden: Springer.

Guss, K. (Ed.). (2019). Psychologische Forschung - Die Jahrgänge 1922 bis 1938. Borgentreich: Verlag der Ostwestfalen-Akademie.

Harrington, A. (1996). Reenchanted Science: Holism in German Culture from Wilhelm II to Hitler. Princeton: Princeton University Press.

Harrower, M. (1983). Kurt Koffka: an unwitting self-portrait. Gainsville: University Presses of Florida, xvi-334.

Heider, F. (1983). The life of a psychologist: An autobiography. Lawrence: University Press of Kansas.

Henle, M. (Ed.). (1961). Documents of Gestalt psychology. Berkley and Los-Angeles: University of California Press.

King, D. B., Wertheimer, M. (2005). Max Wertheimer and Gestalt theory. New Brunswick, NJ: Transaction Publishers.

Koffka, K. (1922). Perception: An introduction to the Gestalt-theorie. Psychological Bulletin, 19(10), 531-585.

Köhler, W. (1929). Gestalt psychology. New York: Liveright.

Krementsov, N. L. (1997). Stalinist science. Princeton: Princeton University Press.

Leeper, R. W. (1943). Lewin's topological and vector psychology: A digest and a critique. Eugene, Oregon: University of Oregon.

Lewin, K. (1936). Principles of Topological Psychology. New York \& London: McGraw-Hill Book Company.

Lewin, K. (1951). Field Theory of Social Science: Selected Theoretical Papers (D. Cartwright, Ed.). New York: Harper \& Row.

Metzger, W. (1941). Psychologie. Die Entwicklung ihrer Grundannahmen seit der Einführung des Experiments. Berlin: Springer.

Padovani, F. (2013). Genidentity and topology of time: Kurt Lewin and Hans Reichenbach. In N. Milkov (Ed.), The Berlin Group and the philosophy of logical empiricism (pp. 97-122). Dordrecht: Springer. 


\section{GESTALT THEORY, Vol. 43, No.3}

Stock, A. (2015). Wertheimer, Max. In U. Wolfradt, E. Billmann-Mahecha, \& A. Stock (Eds.), Deutschsprachige Psychologinnen und Psychologen 1933-1945. Ein Personenlexikon, ergänzt um einen Text von Erich Stern (pp. 478-480). Wiesbaden: Springer.

Toccafondi, F. (2002). Receptions, readings and interpretations of Gestaltpsychologie. Gestalt Theory, 24(3), 199-211.

Van der Veer, R., Lück, H. E. (2002). Berliner Gestaltpsychologie in Aktion: Zur Diskussion der Experimente von Tamara Dembo. Psychologie Und Geschichte, 10(1-2), 40-55.

Wertheimer, M. (1980). Max Wertheimer, Gestalt prophet. Gestalt Theory, 2, 3-17.

Wolfradt, U., Billmann-Mahecha, E., Stock, A. (Eds.). (2015). Deutschsprachige Psychologinnen und Psychologen 1933-1945. Ein Personenlexikon, ergänzt um einen Text von Erich Stern. Wiesbaden: Springer.

Yasnitsky, A. (2009). Vygotsky Circle during the Decade of 1931-1941: Toward an Integrative Science of Mind, Brain, and Education. Ph.D. dissertation, University of Toronto.

Yasnitsky, A. (2011). Vygotsky Circle as a personal network of scholars: Restoring connections between people and ideas. Integrative Psychological and Behavioral Science, 45(4), 422-457.

Yasnitsky, A. (2014). Field theory. In T. Teo (Ed.), Encyclopedia of Critical Psychology (pp. 730-733). New York: Springer.

Yasnitsky, A. (2018). Vygotsky: An Intellectual Biography. London \& New York: Routledge.

Yasnitsky, A. (Ed.). (2019). Questioning Vygotsky's Legacy: Scientific Psychology or Heroic Cult. London \& New York: Routledge.

Yasnitsky, A. (Ed.). (2021a). A History of Marxist Psychology: The Golden Age of Soviet Science. London \& New York: Routledge.

Yasnitsky, A. (2021b). Cultural historical gestalt theory and beyond: Toward pragmatic anthropology. Gestalt Theory - An International Multidisciplinary Journal.

Yasnitsky, A. (2021c, April). Scientific revolution without any revolution whatsoever: The psychology of the 21st century as 'eternal return' to its roots. Presented at the Guest Lecture, United Arab Emirates University, Al Ain. Retrieved from http://individual.utoronto.ca/yasnitsky/texts/Yasnitsky_2021_revNoRev.pdf

Yasnitsky, A., Van der Veer, R. (Eds.). (2016). Revisionist Revolution in Vygotsky Studies. London \& New York: Routledge.

Anton Yasnitsky, United Arab Emirates University, Al Ain, UAE.

E-mail: anton.yasnitsky@gmail.com

Orcid: 0000-0002-9574-535X 